\title{
A position statement and practical guide to the use of particulate filtering facepiece (N95, FFP2, or equivalent) respirators for South African health care workers exposed to respiratory pathogens including M. tuberculosis and SARS-
}

\section{CoV-2}

\section{A position statement endorsed by the}

South African Thoracic Society, Infection Control Society of South Africa, South African Society of Anaesthesiologists, Critical Care Society of Southern Africa, South African Medical Association, South African HIV Clinicians Society, Infectious Diseases Society of South Africa, South African Heart Association, TB Proof, and Free of TB

\section{Affiliations}

1. Centre for Lung Infection and Immunity, Division of Pulmonology, Department of Medicine and UCT Lung Institute \& South African MRC/UCT Centre for the Study of Antimicrobial Resistance, University of Cape Town, Cape Town, South Africa.

2. Faculty of Infectious and Tropical Diseases, Department of Immunology and Infection, London School of Hygiene \& Tropical Medicine, London, United Kingdom

3. The Aurum Institute, Johannesburg, South Africa

4. School of Public Health, University of the Witwatersrand, Johannesburg, South Africa

5. TB Centre, London School of Hygiene \& Tropical Medicine, London, United Kingdom

6. School of Public Health and Family Medicine, University of Cape Town, Cape Town, South Africa

7. TB Proof, South Africa

8. Gateway Private Hospital Medical Centre, Umhlanga Ridge, South Africa

9. Principal Investigator Durban International Clinical Research Site

10. Division of Pulmonology and Department of Medicine, University of Cape Town \& Groote Schuur Hospital

11. Division of Pulmonology, Department of Medicine, Stellenbosch University and Tygerberg Hospital, Cape Town, South Africa

12. Clinical Trials Unit, University of Cape Town Lung Institute, South Africa

13. Division of Pulmonology, Department of Medicine, School of Clinical Medicine, Faculty of Health Sciences, University of the Witwatersrand, Johannesburg, South Africa

14. Clinical Microbiology \& Infectious Diseases, School of Pathology of the NHLS \& University of the Witwatersrand, Johannesburg, South Africa

15. Dept of Critical Care, Faculty of Health Sciences, University of the Witwatersrand, Johannesburg, South Africa 
16. Department of Internal Medicine, School of Clinical Medicine, Faculty of Health Sciences, University of the Witwatersrand, Johannesburg, South Africa

17. Department of Medicine, Divisions of Pulmonology and Critical Care, Charlotte Maxeke Johannesburg Academic Hospital and Faculty of Health Sciences, University of the Witwatersrand, Johannesburg, South Africa.

18. Department of Pulmonology, Nelson R Mandela School of Medicine, College of Health Sciences, University of KwaZulu Natal, Durban, South Africa

19. Ezintsha, Faculty of Health Sciences, University of the Witwatersrand

20. Greys Hospital, Pietermartizburg, South Africa

21. Division of Occupational Medicine, School of Public Health and Family Medicine, University of Cape Town, South Africa

22. Division of Cardiology, Department of Medicine, University of Cape Town and Groote Schuur Hospital, Cape Town, South Africa

23. Nuffield Department of Primary Care Health Sciences, University of Oxford, United Kingdom

24. Department of Infectious Diseases, Division of Internal Medicine, Nelson R Mandela School of Medicine, University of KwaZulu-Natal, Durban, South Africa

25. Southern African HIV Clinicians Society

26. Perinatal HIV Research Unit (PHRU), University of the Witwatersrand, South Africa.

27. Johns Hopkins University Center for TB Research, Baltimore MD

28. National Institute for Communicable Diseases, Division of the National Health Laboratory Service, Johannesburg, South Africa

29. Clinical Microbiology \& Infectious Diseases, School of Pathology, Faculty of Health Sciences, University of the Witwatersrand, Johannesburg, South Africa

30. Division of Infectious Diseases, Department of Medicine, University of the Witwatersrand

31. TB HIV Care, Cape Town, South Africa

32. Division of Medical Virology, Faculty of Medicine and Health Sciences, Stellenbosch University and National Health Laboratory Service Tygerberg

33. South African Society of Anaesthesiologists

34. Department of Anaesthesia, Faculty of Health Sciences, University of the Witwatersrand, Johannesburg, South Africa

35. Division of Critical Care, Chris Hani Baragwanath Hospital and University of the Witwatersrand, Johannesburg, South Africa.

36. Dept of Paediatrics \& Child Health, Red Cross Children's Hospital and SA-MRC unit on Child \& Adolescent Health, University of Cape Town, South Africa

37. Department of Medicine, Vanderbilt University, Nashville, TN, USA

\section{Corresponding author}

Keertan Dheda, Centre for Lung Infection and Immunity, Division of Pulmonology, Department of Medicine and UCT Lung Institute, Groote Schuur Hospital, Old Main Building, Observatory Cape Town, 7925

Email: keertan.dheda@uct.ac.za 
This is a preprint that has been submitted to the African Journal of Thoracic and Critical Care Medicine.

\section{Executive summary}

2 Initial recommendations for protecting health care workers (HCWs) against COVID-19 were based on an

3 early and incomplete understanding of severe acute respiratory syndrome coronavirus 2 (SARS-CoV-2)

4 transmission; namely, that it occurred mainly via large respiratory droplets ( $>10 \mu \mathrm{m})$ that were inhaled into

5 the nasopharynx, directly inoculated onto mucous membranes, deposited on the skin and transferred by direct contact, or transferred indirectly by infected fomites. There is now substantial evidence to show that transmission by aerosol (particles $<10 \mu \mathrm{m}$ that can remain suspended for hours before being inhaled) is likely the predominant mode, with skin- and fomite-based transmission thought to play a lesser role. Many international organisations have updated their personal protective equipment (PPE) guidelines accordingly. Because N95 or equivalent particulate filtering facepiece respirators (henceforth referred to as 'respirators') are more effective than surgical masks against bioaerosols, the World Health Organization, United States Centers for Disease Control and Prevention, and European Centre for Disease Control and Prevention all now recommend that HCWs wear a respirator when caring for individuals thought to have COVID-19. In South Africa, however, surgical masks are still recommended for the routine care of individuals with possible or confirmed COVID-19, with respirators reserved for so-called aerosol-generating procedures. In contrast, South African guidelines recommend the use of respirators for routine care of all individuals with possible or confirmed tuberculosis (TB), which is transmitted almost exclusively via aerosol.

In health facilities in South Africa, TB and COVID-19 have similar presentations, may occur together, and often have overlapping risk factors and imaging characteristics. Distinguishing between TB and COVID-19 in individual patients is challenging without examination and investigation, both of which may entail prolonged exposure of HCWs to potentially infectious individuals. Symptom-based triage has limited utility in identifying risk: asymptomatic transmission of SARS-CoV-2 is well recognised, and a high proportion of individuals with pulmonary TB also may not have symptoms. The prevalence of undiagnosed respiratory disease is therefore likely to be significant in many general clinical areas (e.g., waiting areas). HCWs are known to be at higher risk of TB than the general population and thousands of HCWs have developed COVID- 
19 since the start of the pandemic. A proportion of South African HCWs are also HIV positive, placing them at increased risk of severe COVID-19 disease, hospital admission, and death.

Improving infection prevention and control involves implementing a package of administrative,

environmental, and personal protection measures, along with substantial reorganisation of systems, care processes, and guidelines to prioritise $\mathrm{HCW}$ and patient safety. While this will take time, it is unacceptable to expose HCWs to increased risk until such changes are made. We propose that the South African health system adopts a target of 'zero harm', aiming to completely eliminate transmission of respiratory pathogens to all individuals in every health care setting. Accordingly, in line with the precautionary principle, we recommend the use of high quality, fit-tested respirators by all frontline or non-frontline staff (clinical and non-clinical) during activities that involve contact or sharing air in indoor spaces with individuals who (i) have not yet been clinically evaluated or (ii) are thought or known to have TB and/or COVID-19, or other potentially harmful respiratory infections including influenza, measles, and varicella.

We recognise that this will be challenging, not least due to global and national shortages of PPE. The National Department of Health's policy for the regulation of respiratory protective equipment enables a robust framework for manufacture, assessment, and quality control and has been well supported by local manufacture and the South African Department of Trade, Industry and Competition. Manufacturers should explore adaptations to improve comfort of respirators and reduce barriers to communication. The wider use of respirators does not replace the need for structural changes to improve the safety of health facilities: persistent advocacy and research around potential systems change remain essential. 
This is a preprint that has been submitted to the African Journal of Thoracic and Critical Care Medicine.

45

\section{Introduction}

Almost 2.5 million South Africans have tested positive for severe acute respiratory syndrome coronavirus 2 (SARS-CoV-2) since March 2020, and around 70,000 have died in hospitals from COVID-19. ${ }^{[1]}$ Although SARSCoV-2 was initially thought to be spread predominantly through droplet or direct contact, there is strong evidence now that aerosol-based transmission is likely the dominant route of spread. ${ }^{[2]}$ This is especially important in the light of the circulation (at the time of writing) of the Delta variant, which is more transmissible than the original virus or Beta variant. ${ }^{[3]}$ Because many people infected with SARS-CoV-2 are asymptomatic, and because any respiratory symptoms experienced are often non-specific, clinically distinguishing people with COVID-19 from other respiratory infections is impossible. ${ }^{[4]}$ Frontline health care workers (HCWs) are highly exposed and at high risk of infection, as shown by the thousands who have been infected, developed illness, and died. ${ }^{[5]}$

HCWs in high tuberculosis (TB) burden countries are already at high risk of TB infection and disease. ${ }^{[6-9]}$ Despite significant progress, TB incidence in South Africa remains high at over 600 per 100,000 population (around 360,000 new cases per year), and it has consistently been the country's leading cause of death, responsible for $\sim 60,000$ deaths every year. ${ }^{[10]}$ Management of a respiratory pandemic is more complex in high TB burden countries such as South Africa: in addition to previous or current TB, individuals seeking care often have a history of one or more of HIV, tobacco smoking, biomass fuel exposure, outdoor air pollution, or exposure to mining dust, which considerably expands the differential diagnosis in those presenting with respiratory symptoms. ${ }^{[11-13]}$ Presentations and risk factors can be difficult to differentiate without additional time and investigation, both of which can increase the likelihood and duration of HCW exposure to infectious individuals. TB may also be a specific factor placing people at increased risk of developing COVID19. ${ }^{[14]}$

International guidelines recommend that HCWs should be wearing N95 or equivalent particulate filtering facepiece respirators ("respirators") for routine care of individuals with possible TB or COVID-19 (though World Health Organization [WHO] COVID-19 guidelines are not entirely consistent). ${ }^{[15,16]}$ At the time of 
writing, however, South African COVID-19 guidelines state that this level of protection is needed only for 'aerosol-generating' procedures (AGPs), such as intubation and bronchoscopy. ${ }^{[16-18]}$ Recent studies suggest that coughing - common in both TB and COVID-19 pneumonitis - may produce as much (or more) aerosol than some AGPs. ${ }^{[19-21]}$ There is also strong evidence that, like Mycobacterium tuberculosis $(M . t b),{ }^{[2,22]}$ SARSCoV-2 is transmitted also by aerosol; this includes a wealth of epidemiological data (recently summarised by Greenhalgh and colleagues), ${ }^{[2]}$ laboratory experiments showing that the virus remains viable in aerosols for up to 3 hours, ${ }^{[23]}$ detection of viable virus in air samples from COVID-19 infected persons and animals, ${ }^{[24-26]}$ and identification of SARS-CoV-2 in hospital air filters and building ducts. ${ }^{[27]}$ In other experiments, activities like speaking, shouting, and singing have been shown to produce substantial amounts of infectious aerosol, as has the use of oxygen. ${ }^{[28]}$ The definition of aerosol-generating procedure in South African guidelines is therefore overly restrictive ${ }^{[18]}$ and there is a pressing need to ensure that $\mathrm{HCWs}$ are adequately protected from both M.tb and SARS-CoV-2.

In this article, we aim to build the case for national policies to support more widespread and consistent use of respirators by HCWs in high TB burden countries like South Africa, both in the context of the ongoing COVID-19 pandemic and beyond. We make specific recommendations for situations in which respirators should be worn by HCWs in South Africa and discuss some of the additional efforts needed to sustain this policy.

\section{Making the argument}

\section{Health care workers are left unprotected}

Effective implementation of infection prevention and control (IPC) in health facilities is important to avoid 'institutional amplification' of epidemics, ${ }^{[29]}$ to protect the people who attend and work there, and to preserve the health workforce - a critical issue at all times, and more so during a pandemic. TB in HCWs is a persistent problem: numerous studies over the last 30 years have shown that HCWs in high TB burden countries are more likely than the general population to develop both latent TB infection and active TB disease, largely because of occupational exposure. ${ }^{[6,7,30-33]}$ Many HCWs may have underlying vulnerability to 
severe disease, for which optimal protection is essential, ${ }^{[34]}$ and, in addition to the risk to HCWs themselves, there are also risks of transmission to their families, vulnerable household members, and patients. The thousands of HCWs who have developed and died from COVID-19 in the last 18 months clearly demonstrates both the risks faced by HCWs and the insufficient priority given to HCW safety. ${ }^{[5,35-38]}$

HCWs, like all other South African workers, have a right to a safe working environment. ${ }^{[39]} \mathrm{HCWs}$ worldwide have paid a disproportionate price for governments' and health systems' lack of foresight, lack of preparation, and underinvestment in pandemic preparedness; ${ }^{[00]}$ this has manifested, among other things, as inadequate or insufficient personal protective equipment (PPE) for frontline and other staff. ${ }^{[41,42]}$ Indeed, it was shown recently that none of the tested "KN95" respirators evaluated in South Africa met stipulated safety standards for HCW protection. ${ }^{[43]}$ We echo calls by other authors for urgent research, funding, and prioritisation of IPC and HCW protection ${ }^{[44]}$ and for more comprehensive approaches to occupational health. ${ }^{[45,46]}$ Though we recognise that systemic changes will take time to enact, it is unacceptable that HCWs remain at risk until such changes are made.

\section{On the frontline it is impossible to differentiate between TB, SARS-CoV2 and other infections} Because of the multitude of possible presentations, non-specific symptoms (e.g., fever, cough), overlapping risk factors, and likelihood of dual infection, ${ }^{[11-14,47,48]}$ it is impossible to make a specific diagnosis of TB, COVID-19, or other respiratory infection in most South African health facilities without detailed clinical assessment and laboratory investigation, usually over a period of at least 24-72 hours (the turnaround time of most diagnostic tests). If the HCW is not adequately protected, this represents is a major opportunity for transmission to occur. Transmission of SARS-CoV-2 by asymptomatic individuals has been widely documented, ${ }^{[4]}$ and the burden of 'subclinical' $\mathrm{TB}^{[49]}$ in South Africa is increasingly evident. The recent national TB prevalence survey found that around half of the people in the community with confirmed pulmonary TB did not have symptoms suggestive of $\mathrm{TB}^{[50]}$ and a recent study in KwaZulu-Natal showed similar findings among adults attending primary health care clinics. ${ }^{[1]}$ 
119 Symptom screening cannot differentiate between TB and other respiratory infections. TB can often present 120 as acute pneumonia or acute lower respiratory tract infection (LRTI), and M.tb may be amongst the most 121 common pathogens isolated in this context in Asian and African settings (reviewed in detail in a recent 122 article). ${ }^{[47]}$ In a large study from South Africa $(n \approx 2500$ patients), a symptom duration threshold of $>14$ days 123 was unable to distinguish between TB and other respiratory pathogens, and, in those with LRTI of less than 12414 days duration, TB was the microbiologically-proven diagnosis in a staggering 18\% of patients. ${ }^{[52]}$ This 125 figure is remarkable, considering that in patients with acute LRTI a microbiological diagnosis is made in only $126 \sim 50 \%$ of cases.

127 Triage, based on symptom screening, is challenging to perform consistently and has been shown to be sub128 optimally implemented at PHC clinics across the country. ${ }^{[53,54]}$ In addition, adults accompanying children or 129 other vulnerable individuals may not be screened and may be undetected sources of M.tb or SARS-CoV-2.

130 This means that potentially infectious individuals with undetected disease (with or without symptoms) may 131 remain in general patient streams in perceived 'lower risk' areas, with subsequent inappropriate use of less 132 effective PPE by HCWs.

133 As discussed below, current guidance recommends use of different PPE for different 'types' of patients (e.g., 134 respirators only when in contact with individuals with 'possible' or 'known' TB or COVID-19). However, as we 135 have emphasised, it is almost impossible to estimate who is likely to have TB or COVID-19 (or another 136 respiratory infection, such as influenza or bacterial or fungal pneumonia). Additionally, without information 137 on infectiousness, ventilation, occupancy of rooms, and duration of exposure, ${ }^{[55]}$ it is difficult to reliably 138 estimate the risk of transmission in any given space at any given time. It is therefore unrealistic to expect 139 individual HCWs to make repeated assessments of risk during the course of a working day and adjust their 140 PPE accordingly, particularly at a time when the health system is under pressure. ${ }^{[56,57]}$

141 SARS-CoV-2 and M.tb are transmitted by aerosol: particulate filtering facepiece respirators offer 142 better protection 
Person-to-person transmission of SARS-CoV-2 is currently understood to occur predominantly by two routes.

144 First, via larger respiratory droplets (size $>10 \mu \mathrm{m}$ ), which fall rapidly to the ground or onto surfaces droplets of size $10 \mu \mathrm{m}$ and $100 \mu \mathrm{m}$ take $\sim 10$ minutes and $\sim 6$ seconds, respectively, to fall to the ground. ${ }^{[58]}$ Such droplets may be inhaled or deposited into the nasopharynx or directly inoculated onto mucous membranes (eyes, mouth, upper pharynx) or the skin, with subsequent person-to-person transfer by via direct contact or infected fomites. Second, via aerosol: particles produced through coughing, speech, singing, and "aerosol-generating procedures", which, after desiccation, are usually up to $10 \mu \mathrm{m}$ in diameter, can remain suspended in the air for several hours, and may be inhaled into the lungs (small airways and alveoli) of another person. ${ }^{[22,59-62]}$ The second route, sometimes referred to as airborne transmission, is also the main route of transmission of the measles virus and $M . t b .{ }^{[5,63]}$ However, is important to note that terminology (airborne vs. aerosol vs. respiratory droplets) is not standardised or well defined, and thus airborne spread is likely due to production of a continuum of virus-containing droplet sizes that may be deposited in the upper and/or lower respiratory tract of susceptible individuals. ${ }^{[22]}$

Early in the pandemic, SARS-CoV-2 was thought to be transmissible only via large droplets/fomites, and precautions therefore centred on restricting close contact, cleaning surfaces, and handwashing. ${ }^{[64,65]}$ However, research on aerosolisation has shown that respiratory particle sizes vary widely, and that smaller particles $(<5 \mu \mathrm{m})$ are more likely to contain pathogen. ${ }^{[22]}$ The high likelihood of considerable aerosol transmission of SARS-CoV-2 ${ }^{[2,66-68]}$ has now been acknowledged by the WHO and the United States Centers for Disease Control and Prevention (US CDC), which recently made recommendations around improving ventilation of indoor spaces as part of coronavirus-related IPC. ${ }^{[69,70]}$ Ventilation is important for mitigating aerosol transmission: increasing the number of air changes per hour means that suspended particles are more likely to be removed before they can be inhaled. ${ }^{[71,72]}$ Ten cogent reasons, including underlying evidence, as to why aerosol-based transmission is an important and co-dominant route of SARS-CoV-2 transmission were recently elegantly summarised in the Lancet. $^{[2]}$ 
167 The evidence around the relative efficacy of masks and respirators against aerosols is also reasonably clear. 168 In laboratory studies, respirators (filtering face piece [FFP] 2 or FFP3) were shown to be 16-108 times more 169 effective than fluid repellent surgical masks (FRSMs) in filtering aerosolised sodium chloride. ${ }^{[73]}$ Clinical 170 studies are less definitive, in part because of variation in methodologies and definitions of exposure, 171 confounding, and issues with powering of studies. At least two studies, however, have shown statistically 172 important reductions in risk with quality respirator use compared with surgical masks, particularly when 173 used continuously (as opposed to 'targeted' use) and when individuals were exposed to clinical respiratory 174 illness. ${ }^{[73-77]}$

\section{Current South African guidance is at odds with international recommendations}

176 Table 1 summarises South African and global guidance around respirator use for personal protection against 177 M.tb and SARS-CoV-2. The majority of national and international bodies (other than Public Health 178 England) $)^{[78]}$ recommend the use of respirators for routine care of individuals with possible or confirmed 179 COVID-19 or TB. South Africa, at present, recommends an N95 respirator for care of individuals with possible 180 or confirmed TB, but only a surgical mask for routine care of individuals with possible or confirmed COVID-

181 19. ${ }^{[18,79]}$ This does not offer individuals protection against aerosol transmission of SARS-CoV-2 and,

182 importantly, requires HCWs to differentiate between those who may have TB and those who may have 183 COVID-19, which, as outlined above, is difficult if not impossible to do. 
Table 1. International and South African recommendations for use of masks and respirators by health care workers (note the mask terminology used is concordant with what was used in the relevant guideline document)"

\begin{tabular}{|c|c|c|c|c|c|}
\hline \multirow[t]{2}{*}{ Source } & \multirow[t]{2}{*}{ Scope } & \multicolumn{2}{|l|}{ Tuberculosis } & \multicolumn{2}{|l|}{ COVID-19 } \\
\hline & & Routine care* & AGPst & Routine care* & AGPst \\
\hline $\begin{array}{l}\text { South Africa } \\
\text { DoH/NICD }{ }^{[18,79]}\end{array}$ & South Africa & N95 respirator & N95 respirator & Surgical mask & N95 respirator \\
\hline $\mathbf{W H O}^{[16,17]}$ & Global & $\begin{array}{l}\text { Particulate respirator } \\
\text { (high TB burden } \\
\text { settings) } \ddagger\end{array}$ & Particulate respirator & $\begin{array}{l}\text { N95/FFP2/FFP3 } \\
\text { respirator§ }\end{array}$ & $\begin{array}{l}\text { N95/FFP2/FFP3 } \\
\text { respirator }\end{array}$ \\
\hline US CDC ${ }^{[80,81]}$ & United States & $\begin{array}{l}\text { N95 respirator (at } \\
\text { least) }\end{array}$ & $\begin{array}{l}\text { N95 respirator at } \\
\text { least. Consider } \\
\text { elastomeric full- } \\
\text { facepiece respirator } \\
\text { or PAPR }\end{array}$ & $\begin{array}{l}\text { N95 or equivalent or } \\
\text { higher-level } \\
\text { respirator }\end{array}$ & $\begin{array}{l}\text { N95 respirator or } \\
\text { respirators that offer } \\
\text { a higher level of } \\
\text { protection }\end{array}$ \\
\hline $\mathrm{PHE}^{[78]} / \mathrm{NICE}^{[82]}$ & $\begin{array}{l}\text { England/ } \\
\text { United } \\
\text { Kingdom }\end{array}$ & FFP2 respirator & $\begin{array}{l}\text { FFP2 or FFP3 } \\
\text { respirator }\end{array}$ & $\begin{array}{l}\text { Fluid-resistant } \\
\text { surgical face mask } \\
\text { (Type IIR) }\end{array}$ & $\begin{array}{l}\text { FFP3 respirator or } \\
\text { hood }\end{array}$ \\
\hline $\operatorname{ECDC}^{[83,84]}$ & Europe & Respirator & Respirator & Respirator & Respirator \\
\hline $\begin{array}{l}\text { India } \\
\text { MoHFW } \\
\text { Mo5,86] }\end{array}$ & India & N95 respirator & N95 respirator & N95 respirator\| & N95 respirator \\
\hline
\end{tabular}

\#Terms used for mask/respirator types are consistent with those used in the respective guidelines. WHO defines 'particulate respirators' as those meeting N95 or FFP2 standards. ECDC defines 'respirators' as those meeting FFP2 or FFP3 standards.

*Routine care of people with possible or confirmed TB or COVID-19

†AGPs (aerosol-generating procedures) include endotracheal intubation/extubation; respiratory tract suctioning; manual ventilation; tracheotomy; tracheostomy; bronchoscopy; surgery or post mortems involving high-speed cutting (of the respiratory tract); certain dental procedures; non-invasive and high-frequency oscillating ventilation; use of high flow nasal oxygen, sputum induction; chest physiotherapy; cardiopulmonary resuscitation; and collection of naso- and oropharyngeal swabs

$\ddagger^{\prime \prime}$...to reduce $M$. tuberculosis transmission to health workers, persons attending health care facilities or other persons in settings with a high risk of transmission"

$\S^{\prime \prime . . . f o r ~ w o r k ~ w i t h ~ i n f e c t e d ~ p e o p l e ~ i n ~ i n d o o r, ~ c r o w d e d ~ p l a c e s ~ w i t h o u t ~ a d e q u a t e ~ v e n t i l a t i o n " ~}$

$\| "$ "...in all patient care areas, while providing patient care"

AGP: aerosol-generating procedure; CDC: Centers for Disease Control and Prevention; COVID-19: coronavirus disease 2019; ECDC: European Centre for Disease Control and Prevention; FFP: filtering face piece; HCW: health care worker; IDSA: Infectious Diseases Society of America; MoHFW: Ministry of Health and Family Welfare; n/s: not specified; NICD: National Institute for Communicable Diseases; NICE: National institute for Health and Care Excellence; PAPR: powered air-purifying respirator; PHE: Public Health England; TB: tuberculosis; US: United States; WHO: World Health Organization

In summary (and sidestepping controversies about whether surgical masks or respirators are essential for burden settings. It is impractical and not clinically meaningful to provide pathogen-specific guidance on masking. We have therefore provided guidance below in the context of routine exposure to acute 


\section{Recommendations}

\section{Zero transmission, zero harm: our recommendations for the widespread consistent use of 213 particulate respirators in high TB burden settings}

214 We propose that the health system should aim for a target of 'zero transmission, zero harm': a position that builds on the precautionary principle ${ }^{[87]}$ and the foundational ethical value of 'do no harm' to suggest that the health system's duty of care extends beyond patients to include its workforce. The principle of 'zero harm' has been used most widely to refer to efforts to improve patient safety, ${ }^{[88]}$ but here we use the term specifically around disease transmission. It is unacceptable that any person should be infected with M.tb or SARS-CoV-2 as a result of exposure in a health care facility, and the health system should aim to eliminate transmission in all health care settings. Clearly this will require prioritisation and significant long-term investment in a range of IPC measures, including consideration of building design, ventilation, ultraviolet germicidal irradiation (UVGI) systems, and organisation of services to reduce overcrowding and enable consistent implementation of administrative measures such as triage, respiratory isolation, prompt treatment, and disinfection of surfaces and equipment. This also means that HCWs are entitled to, and should have access to, high quality PPE sufficient to protect against both droplet and aerosol transmission, with efforts made to minimise exposure.

1. Particulate filtering facepiece respirators should be worn by:

a. all staff (clinical and non-clinical) during activities that involve contact or sharing air in indoor spaces (more so if poorly ventilated) with individuals who (i) have not yet been clinically evaluated or (ii) are thought or known to have TB and/or COVID-19 (this will likely include waiting areas, emergency departments, clinic consultation rooms, and certain inpatient wards and high care/intensive care units);

b. frontline staff in clinical areas who are in contact with patients thought or known to have TB, COVID-19, or other respiratory infection, including influenza, measles, and varicella (likely 
This is a preprint that has been submitted to the African Journal of Thoracic and Critical Care Medicine.

areas include emergency departments, medical admissions units, and 'patients under investigation' [PUI] wards); and

c. any staff involved in high risk or aerosolising procedures involving individuals thought or known to have TB or COVID-19 (e.g., bronchoscopy, open or closed suctioning of the airway, non-invasive ventilation, oxygen, and dental procedures, among others).

2. Respirators (N95, FFP2, and other equivalent respirators, e.g., quality-assured KN95 masks) should fulfil the following requirements, per criteria set out by South Africa's National Department of Health ${ }^{[89]}$ and the National Institute for Occupational Safety and Health (NIOSH; see Box 1). ${ }^{[90]}$

a. All respirators should be accompanied by Homologation Certificates, proof of international compliance, and quality certificates. The filter designation, manufacturer, model number, and certification approval number should be displayed on the body of the respirator.

b. All respirators require a clear physical marking with 1 ) the manufacturer/brand name/registered trademark; 2) an alphanumeric rating as recognised (e.g., FFP2, FFP3, N95, KN95); 3) a standard compliance label showing the standard/s the device has met; 4) the size of the respirator, model number, and lot number; and 5) any other mandatory markings. 


\section{Certification}

All particulate filtering facepiece respirators sold should be accompanied by Homologation Certificates, proof of international compliance (in the case of imported RPE including NIOSH approvals, European Union certifications, CE marking reports, and complete FDA registrations) and quality certificates. The minimum required stipulation is:

1. Total inward leakage using quantitative and/or qualitative Fit tests (performed at facility level on individuals);

2. Determination of particulate filter penetration (PFP) with the minimum testing requirement being to $\mathrm{NaCl}$ filtration (and only where possible to paraffin oil and latex particles);

3. Determination of flow resistance (inhalation resistance at a minimum, but preferably inhalation and exhalation resistance with the latter mandatory for valved respirators);

4. Flammability testing;

5. Fluid resistance test (this test is not mandatory at this time owing to capacity and development constraints in lab testing in South Africa). Where fluid resistance testing has not been conducted by a verified international lab but all other local tests pass, the recommendation is for mandatory visor usage to protect against respirator fluid exposure.

\section{Metrology Notification}

All filtering facepiece respirators (SAHPRA Class B device) in the interests of identification, safety and to ensure that homologation is possible and accurate should have a clear physical marking/stamp on each mask or respirator with the mandatory (in bold) minimum information being:

1. Manufacturer/brand name/registered trademark or easily understood abbreviation

2. The mask or respirator efficiency classification; an alphanumeric rating as recognised (e.g., FFP2, FFP3, N95, KN95)

3. Standard Compliance Label that indicates the local SANS standard showing the device has been tested against and passed

4. Size of the respirator, model number and lot number;

5. Any other mandatory markings as required by SANAS, NRCS, SAHPRA, other national regulator or standard and as may be required by the Legal Metrology Act, 2014 (Act 9 of 2014).

Adapted from the South Africa National Department of Health's Policy for the Regulation of Quality Respiratory Protective Equipment (RPE) Supply in Healthcare (2020) ${ }^{[89]}$

FDA: United States Food and Drug Administration; NRCS: National Regulator for Compulsory Specifications; RPE: respiratory protective equipment; SAHPRA: South African Health Products Regulatory Authority; SANAS: South African National Accreditation System; SANS: South African Bureau of Standards

3. The respirator should, at minimum, be evaluated by qualitative fit testing. ${ }^{[91]}$ Fit testing forms an indispensable part of achieving the objective filtration of virus and bacteria and should be carried out at least annually for every HCW required to wear a respirator, in accordance with the respirator's brand and size. Additional fit testing is generally recommended if the subject experiences a weight change of $\geq 10 \mathrm{~kg}$ or has significant dental changes, reconstructive surgery, or 
facial disfigurement. ${ }^{[89]}$ We recommend that health care facilities have access to low-cost qualitative fit testing equipment (e.g., the $3 \mathrm{M}$ Qualitative Fit Test Apparatus FT-10) ${ }^{[43]}$ so that respirators and wearers can be evaluated. Qualitative fit testing is simpler and cheaper than quantitative testing. This may be at individual health care facilities or through local or regional centres. This will also provide regulatory bodies an opportunity to evaluate masks that claim to meet N95 or FFP2 standards and will go towards establishing a 'respiratory protection programme' for HCWs, in line with international guidance. ${ }^{[17]}$ To meet new recommendations by the South African Health Products Regulatory Authority (SAHPRA), ${ }^{[92]}$ regional or national comprehensive testing nodes should be established to perform more rigorous quantitative fit testing (for example, using the ambient aerosol condensation nuclei counter protocol) ${ }^{[91]}$ and evaluation of filtration integrity. There is currently negligible access to such facilities in the South African public or private sectors.

4. It is critical to emphasise that particulate respirators alone are less likely to be effective if other IPC measures are not implemented. Therefore, in line with international IPC guidelines, ${ }^{[16,17]}$ a 'package of care' approach should be adopted, involving administrative controls (e.g., triage and separation of people with infectious or potentially infectious TB, COVID-19, and/or influenza, etc.), environmental controls (minimising crowding, use of UVGI, ensuring good ventilation [at least 6-12 air changes per hour equivalent]), use of other forms of high quality PPE when appropriate (eye protection, gloves, aprons), source control (face coverings for all attendees), physical distancing, and hand hygiene. Attention to IPC must also be maintained in non-clinical areas where transmission potential remains high, for example, staff canteens, rest areas, and changing rooms. Because of the risk of transmission from HCWs to patients, HCWs should also be made aware of their responsibilities to maintain precautions outside of health facilities, for example, during use of public transport; by minimising time spent in poorly ventilated, densely occupied areas; and by maintaining physical distancing, hand hygiene, and use of face coverings. 
We note also that the practice of wearing a surgical mask over a fit tested quality respirator to prevent contamination or improve efficacy is not evidence based, has not been evaluated scientifically, and may unnecessarily increase the work of breathing. Wearing a surgical mask underneath a respirator is not recommended as it is likely to compromise fit and therefore the efficacy of the respirator. In addition, given the occurrence of breakthrough infections with SARS-CoV-2 in individuals who have received a partial or even full vaccination course, ${ }^{[93]}$ no differentiation should be made according to vaccination status as regards use of PPE.

\section{Hurdles and challenges}

Our aim is to make recommendations for measures that will provide the highest level of protection to HCWs and patients, regardless of the logistical obstacles. We recognise, however, that these recommendations may not be straightforward to implement. Health systems have been severely affected by the global shortage of quality respirators and are facing challenges with procurement and manufacturing. The Department of Health should work with manufacturers, regulatory bodies, and other relevant parties to find ways to overcome challenges to better serve HCWs. We also urge manufacturers to explore improving the comfort of respirators and to take measures to reduce barriers to communication (e.g., by using transparent materials to allow lipreading). Innovative methods should be explored to produce new masks (e.g., 3D printing) without compromising on quality. ${ }^{[94,95]}$

The US CDC states that respirators are "meant to be disposed after each use", but also describes contingency strategies in the case of acute shortages or crisis, including 'decontamination' (e.g., with UVGI, hydrogen peroxide, or moist heat; also known as 'reprocessing'), 'extended use' (continuous use of the same respirator for encounters with multiple patients), and 'limited reuse' (use of the same respirator for encounters with multiple patients, with the respirator donned and doffed between encounters). ${ }^{[96]}$ Each approach carries risks, most importantly of reductions in respirator fit and filtration performance, but also of contamination and self-contamination through repeated donning and doffing. ${ }^{\left[{ }^{[97-99]}\right.}$ As such, SAHPRA and Department of Health currently prohibit decontamination/reprocessing of respirators by any method but, in 
the case of shortages or if supply optimisation is required, do support extended use (with no attempts at cleaning or decontaminating and ideally without repeated donning and doffing) of single use respirators for up to $6-8$ hours, depending on the manufacturer. ${ }^{[89]}$

From a long-term IPC perspective, a focus on respirator use risks over-emphasising individual protection, shifting responsibility back to individual HCWs and lessening pressure on the health system to make the structural changes needed to improve the safety of the working environment. We recognise that persistent advocacy and research to support broader systems change is needed. ${ }^{[100,101]}$ As previously suggested, ${ }^{[6]}$ improved routine reporting of the incidence of TB, COVID-19, and other occupationally-acquired illnesses among HCWs will help monitor the longer-term effects of preventive measures and help drive advocacy.

\section{Conclusions}

SARS-CoV-2 and M.tb are transmitted via aerosol. HCWs are at high risk of infection. The use of surgical masks in frontline settings is inappropriate. Fit-tested particulate filtering facepiece respirators provide better protection against infectious aerosols than surgical masks, are already recommended for use by all HCWs in high TB burden countries and many COVID-19 pandemic settings, and should be worn routinely to protect HCWs against TB and COVID-19.

\section{Acknowledgments/ Funding}

KD acknowledges funding from the SA MRC (RFA-EMU-02-2017), EDCTP (TMA-2015SF-1043, TMA-1051TESAll, TMA-CDF2015), UK Medical Research Council (MR/S03563X/1) and the Wellcome Trust (MR/S027777/1). HJZ is funded by the SA-MRC and the UK MRC (GEC1111). FV's unit acknowledges funding from the Bill \& Melinda Gates Foundation (BMGF), South African Medical Research Council, National Institutes for Health, AIDS Fonds, Unitaid, Foundation for Innovative New Diagnostics and the Children's Investment Fund Foundation, amongst others. GJC is funded by NIH/DAIDS, Unitaid, BMGF, CEPI, and ViiV. NN gratefully acknowledges funding from the NRF, SA-MRC, UK MRC, and the Lily and Ernst Haussmann Trust. 


\section{Declaration of interests}

Dr Martinson's institution receives grants from Pfizer for research into pneumonia. All other authors have no interests to declare.

\section{References}

1 National Institute for Communicable Diseases SA. Latest confirmed cases of COVID-19 in South AFrica (25 July 2021). NICD. 2021. https://www.nicd.ac.za/latest-confirmed-cases-of-covid-19-in-south-africa-25-july-2021/ (accessed 2021 Jul 26)

2 Greenhalgh T, Jimenez JL, Prather KA, Tufekci Z, Fisman D, Schooley R. Ten scientific reasons in support of airborne transmission of SARS-CoV-2. Lancet. 2021;397(10285):1603-5.

3 Network for Genomic Surveillance South Africa. SARS-CoV-2 Sequencing Update (19 July 2021). 2021. https://www.nicd.ac.za/wp-content/uploads/2021/07/Update-of-SA-sequencing-data-from-GISAID-19-July2021.pdf (accessed 2021 Jul 27)

4 Qiu X, Nergiz Al, Maraolo AE, Bogoch II, Low N, Cevik M. The role of asymptomatic and pre-symptomatic infection in SARS-CoV-2 transmission-a living systematic review. Clin Microbiol Infect Off Publ Eur Soc Clin Microbiol Infect Dis. 2021;27(4):511-9.

5 Bandyopadhyay S, Baticulon RE, Kadhum M, et al. Infection and mortality of healthcare workers worldwide from COVID-19: a systematic review. BMJ Glob Health. 2020;5(12):e003097.

6 Grobler L, Mehtar S, Dheda K, et al. The epidemiology of tuberculosis in health care workers in South Africa: a systematic review. BMC Health Serv Res. 2016;16(1):416.

7 Uden L, Barber E, Ford N, Cooke GS. Risk of Tuberculosis Infection and Disease for Health Care Workers: An Updated Meta-Analysis. Open Forum Infect Dis. 2017;4(3):ofx137.

8 Adams S, Ehrlich R, Baatjies R, et al. Incidence of occupational latent tuberculosis infection in South African healthcare workers. Eur Respir J. 2015;45(5):1364-73.

9 Jarand J, Shean K, O'Donnell M, et al. Extensively drug-resistant tuberculosis (XDR-TB) among health care workers in South Africa. Trop Med Int Health. 2010;15(10):1179-84.

10 World Health Organization. Tuberculosis profile: South Africa (2019).

https://worldhealthorg.shinyapps.io/tb_profiles/?_inputs_\&entity_type=\%22country\%22\&lan=\%22EN\%22\&iso2= $\% 22 Z$ \%22 (accessed 2021 Jun 6)

11 Brunet L, Pai M, Davids V, et al. High prevalence of smoking among patients with suspected tuberculosis in South Africa. Eur Respir J. 2011;38(1):139-46.

12 van Zyl Smit RN, Pai M, Yew WW, et al. Global lung health: the colliding epidemics of tuberculosis, tobacco smoking, HIV and COPD. Eur Respir J. 2010;35(1):27-33.

13 Lin $\mathrm{H}-\mathrm{H}$, Ezzati M, Murray M. Tobacco smoke, indoor air pollution and tuberculosis: a systematic review and metaanalysis. PLoS Med. 2007;4(1):e20.

14 Boulle A, Davies M-A, Hussey H, et al. Risk factors for COVID-19 death in a population cohort study from the Western Cape Province, South Africa. Clin Infect Dis Off Publ Infect Dis Soc Am. 2020;

15 World Health Organization. Infection prevention and control during health care when coronavirus disease (COVID19) is suspected or confirmed (interim guidance - 12 July 2021). 2021. https://apps.who.int/iris/rest/bitstreams/1356030/retrieve (accessed 2021 Jul 27) 
16 World Health Organization. COVID-19: Occupational health and safety for health workers. Interim guidance - 2 February 2021. 2021. https://apps.who.int/iris/rest/bitstreams/1329986/retrieve (accessed 2021 May 2)

17 World Health Organization. WHO guidelines on tuberculosis infection prevention and control: 2019 update. 2019. https://apps.who.int/iris/bitstream/handle/10665/311259/9789241550512-eng.pdf?ua=1 (accessed 2019 Dec 1)

18 South Africa National Department of Health. COVID-19 Disease: Infection Prevention and Control Guidelines. Version 2 (21st May 2020). 2020. https://www.nicd.ac.za/wp-content/uploads/2020/05/ipc-guidelines-covid-19version-2-21-may-2020.pdf

19 Brown J, Gregson FKA, Shrimpton A, et al. A quantitative evaluation of aerosol generation during tracheal intubation and extubation. Anaesthesia. 2020;10.1111/anae.15292.

20 Shrimpton A, Gregson FKA, Cook TM, et al. A quantitative evaluation of aerosol generation during tracheal intubation and extubation: a reply. Anaesthesia. 2021;76(S3):16-8.

21 Chanpong B, Tang M, Rosenczweig A, Lok P, Tang R. Aerosol-Generating Procedures and Simulated Cough in Dental Anesthesia. Anesth Prog. 2020;67(3):127-34.

22 Fennelly KP. Particle sizes of infectious aerosols: implications for infection control. Lancet Respir Med. 2020;8(9):914-24.

23 van Doremalen N, Bushmaker T, Morris DH, et al. Aerosol and Surface Stability of SARS-CoV-2 as Compared with SARS-CoV-1. N Engl J Med. 2020;382(16):1564-7.

24 Lednicky JA, Lauzardo M, Fan ZH, et al. Viable SARS-CoV-2 in the air of a hospital room with COVID-19 patients. Int $J$ Infect Dis IJID Off Publ Int Soc Infect Dis. 2020;100:476-82.

25 Lednicky JA, Lauzardo M, Alam MM, et al. Isolation of SARS-CoV-2 from the air in a car driven by a COVID patient with mild illness. Int J Infect Dis IJID Off Publ Int Soc Infect Dis. 2021;108:212-6.

26 Kutter JS, de Meulder D, Bestebroer TM, et al. SARS-CoV and SARS-CoV-2 are transmitted through the air between ferrets over more than one meter distance. Nat Commun. 2021;12(1):1653.

27 Nissen K, Krambrich J, Akaberi D, et al. Long-distance airborne dispersal of SARS-CoV-2 in COVID-19 wards. Sci Rep. 2020;10(1):19589.

28 Schijven J, Vermeulen LC, Swart A, Meijer A, Duizer E, de Roda Husman AM. Quantitative Microbial Risk Assessment for Airborne Transmission of SARS-CoV-2 via Breathing, Speaking, Singing, Coughing, and Sneezing. Environ Health Perspect. 2021;129(4):47002.

29 Basu S, Stuckler D, McKee M. Addressing Institutional Amplifiers in the Dynamics and Control of Tuberculosis Epidemics. Am J Trop Med Hyg. 2011;84(1):30-7.

30 Menzies D, Fanning A, Yuan L, Fitzgerald M. Tuberculosis among health care workers. N Engl J Med. 1995;332(2):92-8.

31 Menzies D, Joshi R, Pai M. Risk of tuberculosis infection and disease associated with work in health care settings. Int J Tuberc Lung Dis. 2007;11(6):593-605.

32 Joshi R, Reingold AL, Menzies D, Pai M. Tuberculosis among health-care workers in low- and middle-income countries: A systematic review. PLoS Med. 2006;3(12):2376-91.

33 Baussano I, Nunn P, Williams B, Pivetta E, Bugiani M, Scano F. Tuberculosis among health care workers. Emerg Infect Dis. 2011;17(3):488-94.

34 Ambrosioni J, Blanco JL, Reyes-Urueña JM, et al. Overview of SARS-CoV-2 infection in adults living with HIV. Lancet HIV. 2021;8(5):e294-305.

35 South Africa Ministry of Health. Statement on Health Care Workers that have Acquired COVID-19. 2020. https://storage.googleapis.com/stateless-bhekisisa-website/wordpress-uploads/2020/08/fda38e56-hcw-13august-2020.pdf (accessed 2021 May 4) 
36 Jordan B. Covid-19 killed 339 state health-care workers between March and November. TimesLIVE. 2021. https://www.timeslive.co.za/news/south-africa/2021-01-06-covid-19-killed-339-state-health-care-workersbetween-march-and-november/ (accessed 2021 May 4)

37 Kambhampati AK. COVID-19-Associated Hospitalizations Among Health Care Personnel - COVID-NET, 13 States, March 1-May 31, 2020. MMWR Morb Mortal Wkly Rep. 2020;69.

38 Spencer J, Jewett C. Twelve months of trauma: more than 3,600 US health workers died in Covid's first year. The Guardian. 2021. https://www.theguardian.com/us-news/2021/apr/08/us-health-workers-deaths-covid-lost-onthe-frontline (accessed 2021 May 4)

39 Government of the Republic of South Africa. Occupational Health and Safety Act 85 of 1993. Jul 2, 1993.

40 De Raeve P, Adams E, Xyrichis A. The impact of the COVID-19 pandemic on nurses in Europe: A critical discussion of policy failures and opportunities for future preparedness. Int J Nurs Stud Adv. 2021;3:100032.

41 Saba A, Jika T. Eastern Cape's PPE shortage endangers healthcare workers. The Mail \& Guardian. 2020.

42 World Health Organization. Shortage of personal protective equipment endangering health workers worldwide. 2020. https://www.who.int/news/item/03-03-2020-shortage-of-personal-protective-equipment-endangeringhealth-workers-worldwide (accessed 2021 Jun 8)

43 Mottay L, Le Roux J, Perumal R, et al. KN95 filtering facepiece respirators distributed in South Africa fail safety testing protocols. S Afr Med J. 2020;111(3):234.

44 Griffith DE, Cegielski JP. Tuberculosis Healthcare Workers: There Goes My Hero. Clin Infect Dis Off Publ Infect Dis Soc Am. 2020;

45 Ehrlich R, Spiegel JM, Adu P, Yassi A. Current Guidelines for Protecting Health Workers from Occupational Tuberculosis Are Necessary, but Not Sufficient: Towards a Comprehensive Occupational Health Approach. Int J Environ Res Public Health. 2020;17(11):3957.

46 Bourgeault IL, Maier CB, Dieleman M, et al. The COVID-19 pandemic presents an opportunity to develop more sustainable health workforces. Hum Resour Health. 2020;18.

47 Dheda K, Makambwa E, Esmail A. The Great Masquerader: Tuberculosis Presenting as Community-Acquired Pneumonia. Semin Respir Crit Care Med. 2020;41(4):592-604.

48 Aston SJ, Rylance J. Community-Acquired Pneumonia in Sub-Saharan Africa. Semin Respir Crit Care Med. 2016;37(6):855-67.

49 Frascella B, Richards AS, Sossen B, et al. Subclinical tuberculosis disease - a review and analysis of prevalence surveys to inform definitions, burden, associations and screening methodology. Clin Infect Dis. 2020;ciaa1402.

50 Mvusi L. First National TB Prevalence Survey, South Africa, 2017-19. In: The 51st Union World Conference on Lung Health. 2020.

51 Govender I, Karat AS, Baisley K, et al. Prevalence of Mycobacterium tuberculosis in sputum among adult clinic attendees compared with the surrounding community in rural South Africa: implications for finding the missing millions. 51st World Conf Lung Health Int Union Tuberc Lung Dis. 2020;Abstract EP32-410-24.

52 Walaza S, Tempia S, Dreyer A, et al. The Burden and Clinical Presentation of Pulmonary Tuberculosis in Adults With Severe Respiratory IIIness in a High Human Immunodeficiency Virus Prevalence Setting, 2012-2014. Open Forum Infect Dis. 2017;4(3).

53 Chihota VN, Ginindza S, McCarthy KM, Grant AD, Churchyard GJ, Fielding KL. Missed Opportunities for TB Investigation in Primary Care Clinics in South Africa: Experience from the XTEND Trial. Plos One. 2015;10(9):e0138149. 
54 Kweza PF, Van Schalkwyk C, Abraham N, Uys M, Claassens MM, Medina-Marino A. Estimating the magnitude of pulmonary tuberculosis patients missed by primary health care clinics in South Africa. Int J Tuberc Lung Dis Off J Int Union Tuberc Lung Dis. 2018;22(3):264-72.

55 Yates TA, Khan PY, Knight GM, et al. The transmission of Mycobacterium tuberculosis in high burden settings. Lancet Infect Dis. 2016;16(2):227-38.

56 Amalberti R, Vincent C. Managing risk in hazardous conditions: improvisation is not enough. BMJ Qual Saf. 2020;29(1):60-3.

57 Wizner K, Nasarwanji M, Fisher E, Steege AL, Boiano JM. Exploring respiratory protection practices for prominent hazards in healthcare settings. J Occup Environ Hyg. 2018;15(8):588-97.

58 Wells W. On air-borne infection: Study II. Droplets and droplet nuclei. Am J Epidemiol. 1934;20(3):611-8.

59 Loudon RG, Roberts RM. Droplet expulsion from the respiratory tract. Am Rev Respir Dis. 1967;95(3):435-42.

60 Leung NHL. Transmissibility and transmission of respiratory viruses. Nat Rev Microbiol. 2021;

61 Asadi S, Wexler AS, Cappa CD, Barreda S, Bouvier NM, Ristenpart WD. Aerosol emission and superemission during human speech increase with voice loudness. Sci Rep. 2019;9(1):2348.

62 Stadnytskyi V, Anfinrud P, Bax A. Breathing, speaking, coughing or sneezing: What drives transmission of SARSCoV-2? J Intern Med. n/a(n/a).

63 Churchyard G, Kim P, Shah NS, et al. What We Know About Tuberculosis Transmission: An Overview. J Infect Dis. 2017;216(suppl_6):S629-35.

64 World Health Organization. Infection prevention and control during health care when coronavirus disease (COVID19 ) is suspected or confirmed. (Interim guidance, 29 June 2020). 2020.

https://apps.who.int/iris/rest/bitstreams/1284718/retrieve (accessed 2021 May 3)

65 South Africa National Department of Health. COVID-19 Disease: Infection Prevention and Control Guidelines. Version 1 (April 2020). 2020.

66 Maclntyre CR, Ananda-Rajah MR. Scientific evidence supports aerosol transmission of SARS-COV-2. Antimicrob Resist Infect Control. 2020;9.

67 Tang JW, Bahnfleth WP, Bluyssen PM, et al. Dismantling myths on the airborne transmission of severe acute respiratory syndrome coronavirus-2 (SARS-CoV-2). J Hosp Infect. 2021;110:89-96.

68 Dancer SJ, Tang JW, Marr LC, Miller S, Morawska L, Jimenez JL. Putting a balance on the aerosolization debate around SARS-CoV-2. J Hosp Infect. 2020;105(3):569-70.

69 World Health Organization. Roadmap to improve and ensure good indoor ventilation in the context of COVID-19. 1 March 2021. 2021. https://apps.who.int/iris/rest/bitstreams/1333991/retrieve (accessed 2021 May 2)

70 Centers for Disease Control and Prevention. COVID-19: Ventilation in Buildings [Updated 2 June 2021]. 2021. https://www.cdc.gov/coronavirus/2019-ncov/community/ventilation.html (accessed 2021 Jun 8)

71 Stockwell RE, Ballard EL, O’Rourke P, Knibbs LD, Morawska L, Bell SC. Indoor hospital air and the impact of ventilation on bioaerosols: a systematic review. J Hosp Infect. 2019;103(2):175-84.

72 Chan P-C, Fang C-T. The role of ventilation in tuberculosis control. J Formos Med Assoc. 2021;120(6):1293-5.

73 Ramaraj P, Super J, Doyle R, Aylwin C, Hettiaratchy S. Triaging of respiratory protective equipment on the assumed risk of SARS-CoV-2 aerosol exposure in patient-facing healthcare workers delivering secondary care: a rapid review. BMJ Open. 2020;10(10).

74 lannone P, Castellini G, Coclite D, et al. The need of health policy perspective to protect Healthcare Workers during COVID-19 pandemic. A GRADE rapid review on the N95 respirators effectiveness. PloS One. 2020;15(6):e0234025. 
75 Maclntyre CR, Chughtai AA. A rapid systematic review of the efficacy of face masks and respirators against coronaviruses and other respiratory transmissible viruses for the community, healthcare workers and sick patients. Int J Nurs Stud. 2020;108:103629.

76 Maclntyre CR, Wang Q, Seale H, et al. A randomized clinical trial of three options for N95 respirators and medical masks in health workers. Am J Respir Crit Care Med. 2013;187(9):960-6.

77 Chu DK, AkI EA, Duda S, et al. Physical distancing, face masks, and eye protection to prevent person-to-person transmission of SARS-CoV-2 and COVID-19: a systematic review and meta-analysis. Lancet Lond Engl. 2020;395(10242):1973-87.

78 Public Health England. COVID-19: infection prevention and control (IPC) (version 1.2, updated 1 June 2021 ). 2021. https://assets.publishing.service.gov.uk/government/uploads/system/uploads/attachment_data/file/990923/202 10602_Infection_Prevention_and_Control_Guidance_for_maintaining_services_with_H_and_C_settings_1_.pdf (accessed 2021 Jun 8)

79 South Africa National Department of Health. Practical Manual for Implementation of the National Infection Prevention and Control Strategic Framework. 2020. https://www.nicd.ac.za/wpcontent/uploads/2020/04/Practical-Manual-for-implementation-of-the-National-IPC-Strategic-Framework-March2020-1.pdf (accessed 2021 May 2)

80 Centers for Disease Control and Prevention. Guidelines for Preventing the Transmission of Mycobacterium tuberculosis in Health-Care Settings, 2005. 2005. https://www.cdc.gov/mmwr/preview/mmwrhtml/rr5417a1.htm?s_cid=rr5417a1_e (accessed 2021 Jun 8)

81 Centers for Disease Control and Prevention. Interim Infection Prevention and Control Recommendations for Healthcare Personnel During the Coronavirus Disease 2019 (COVID-19) Pandemic (updated Feb. 23, 2021). 2021. https://www.cdc.gov/coronavirus/2019-ncov/hcp/infection-control-recommendations.html (accessed 2021 Jun 8)

82 Diel R, Nienhaus A, Witte P, Ziegler R. Protection of healthcare workers against transmission of Mycobacterium tuberculosis in hospitals: a review of the evidence. ERJ Open Res. 2020;6(1).

83 European Centre for Disease Prevention and Control. European Union Standards for Tuberculosis Care - 2017 update. 2017. https://www.ecdc.europa.eu/sites/default/files/documents/ESTC-leaflet-September-2018.pdf (accessed 2021 Jun 8)

84 European Centre for Disease Prevention and Control. Infection prevention and control and preparedness for COVID-19 in healthcare settings (Sixth update - 9 February 2021). 2021.

https://www.ecdc.europa.eu/sites/default/files/documents/Infection-prevention-and-control-in-healthcaresettings-COVID-19_6th_update_9_Feb_2021.pdf (accessed 2021 Jun 8)

85 National Centre for Disease Control, Directorate General of Health Services, Ministry of Health and Family Welfare, Government of India. National Guidelines for Infection Prevention and Control in Healthcare Facilities. 2020. https://main.mohfw.gov.in/sites/default/files/National\%20Guidelines\%20for\%20IPC\%20in\%20HCF\%20\%20final\%281\%29.pdf (accessed 2021 Jun 8)

86 Government of India: Ministry of Health and Family Welfare. Clinical management protocol for COVID-19 (in adults) - version 6, 24 May 2021. 2021. https://www.mohfw.gov.in/pdf/COVID19ClinicalManagementProtocolAlgorithmAdults19thMay2021.pdf (accessed 2021 Jun 8)

87 Richter ED, Laster R. The Precautionary Principle, epidemiology and the ethics of delay. Int J Occup Med Environ Health. 2004;17(1):9-16.

88 Davis DJ. Going beyond benchmarks: zero harm for every patient, every time. J Nurs Adm. 2015;45(4):183-4.

89 South Africa National Department of Health. Policy for the regulation of quality respiratory protective equipment (RPE) supply in healthcare (August 2020). 2020. https://www.nicd.ac.za/wp-content/uploads/2020/11/RPE-Policy20-August-2020-Signed.pdf (accessed 2021 Jul 27) 
54790 The National Institute for Occupational Safety and Health. Approved Particulate Filtering Facepiece Respirators. 2020. https://www.cdc.gov/niosh/npptl/topics/respirators/disp_part/default.html

91 Occupational Safety and Health Administration. Fit Testing Procedures (Mandatory). 2004. https://www.osha.gov/laws-regs/regulations/standardnumber/1910/1910.134AppA (accessed 2021 Jun 6)

92 South African Health Products Regulatory Authority. Communication to Stakeholders. MD025: Licensing and Regulatory requirements for the manufacture and distribution of medical and respirator masks during COVID-19. 2020. https://www.sahpra.org.za/wp-content/uploads/2020/09/MD025_Alternative-licensing-and-regulatorypathway-for-masks_September2020_vF.pdf (accessed 2021 Jun 8)

93 Bergwerk M, Gonen T, Lustig Y, et al. Covid-19 Breakthrough Infections in Vaccinated Health Care Workers. N Engl J Med. 2021;0(0):null.

94 McAvoy M, Bui A-TN, Hansen C, et al. 3D Printed frames to enable reuse and improve the fit of N95 and KN95 respirators. MedRxiv Prepr Serv Health Sci. 2020;

95 Imbrie-Moore AM, Park MH, Zhu Y, Paulsen MJ, Wang H, Woo YJ. Quadrupling the N95 Supply during the COVID19 Crisis with an Innovative 3D-Printed Mask Adaptor. Healthcare. 2020;8(3).

96 Centers for Disease Control and Prevention. Implementing Filtering Facepiece Respirator (FFR) Reuse, Including Reuse after Decontamination, When There Are Known Shortages of N95 Respirators (updated 19 October 2020_. Centers for Disease Control and Prevention. 2020. https://www.cdc.gov/coronavirus/2019-ncov/hcp/ppestrategy/decontamination-reuse-respirators.html (accessed $2021 \mathrm{Jul} 30$ )

97 Bergman MS, Viscusi DJ, Zhuang Z, Palmiero AJ, Powell JB, Shaffer RE. Impact of multiple consecutive donnings on filtering facepiece respirator fit. Am J Infect Control. 2012;40(4):375-80.

98 Degesys NF, Wang RC, Kwan E, Fahimi J, Noble JA, Raven MC. Correlation Between N95 Extended Use and Reuse and Fit Failure in an Emergency Department. JAMA. 2020;324(1):94-6.

99 Brady TM, Strauch AL, Almaguer CM, et al. Transfer of bacteriophage MS2 and fluorescein from N95 filtering facepiece respirators to hands: Measuring fomite potential. J Occup Environ Hyg. 2017;14(11):898-906.

100 Kielmann K, Karat AS, Zwama G, et al. Tuberculosis infection prevention and control: why we need a whole systems approach. BMC Infect Dis Poverty. 2020;9(1):56.

101 van der Westhuizen H-M, Nathavitharana RR, Pillay C, Schoeman I, Ehrlich R. The high-quality health system 'revolution': Re-imagining tuberculosis infection prevention and control. J Clin Tuberc Mycobact Dis. 2019;17:100118. 